\title{
Desenvolvimento das farmácias vivas associado a fatores sociodemográficos brasileiros
}

\author{
Development of live pharmacies in association with brazilian sociodemographic factors \\ Desarrollo de farmacias vivas asociadas con factores sociodemográficos brasileños
}

Recebido: 09/01/2022 | Revisado: 14/01/2022 | Aceito: 21/01/2022 | Publicado: 23/01/2022

\author{
Jacqueline Marques da Silva Gondim \\ ORCID: https://orcid.org/0000-0001-7414-9412 \\ Universidade Federal de Mato Grosso do Sul, Brasil \\ E-mail: jacqueline.gondim@ufms.br \\ Elaine Silva de Pádua Melo \\ ORCID: https://orcid.org/0000-0002-4766-7334 \\ Universidade Federal de Mato Grosso do Sul, Brasil \\ E-mail: elaine.melo@ufms.br \\ Ademir da Silva Alves Junior \\ ORCID: https://orcid.org/0000-0002-7000-7182 \\ Universidade Federal de Mato Grosso do Sul, Brasil \\ E-mail: ademir.alves@ufms.br \\ Valter Aragão do Nascimento \\ ORCID: https://orcid.org/0000-0002-9020-8002 \\ Universidade Federal de Mato Grosso do Sul, Brasil \\ E-mail: valter.aragao@ufms.br
}

\begin{abstract}
Resumo
O objetivo desse estudo foi analisar a implementação da Política Nacional de Plantas Medicinais e Fitoterápicos no Sistema Único de Saúde brasileiro por meio das Farmácias Vivas. A metodologia consiste em uma pesquisa documental e bibliográfica, de caráter descritivo, a partir de busca por artigos de periódicos, livros, levantamento de documentos normativos oficiais, em bases de dados como o Portal de Periódicos Capes/MEC, PubMed, Scielo, Google Acadêmico, portal do Ministério da Saúde, Diário Oficial da União, site oficiais das secretarias de saúde, da Anvisa e do IBGE. No período de março de 2020 e outubro de 2020. Para levantamento de ações, políticas públicas e regulatórias no âmbito das plantas medicinais e fitoterápicos, foram buscadas normativas entre os anos de 1982 e 2009. Foi considerado o período de 1983 a 2020 para análise da institucionalização das Farmácias Vivas. Em relação aos recursos públicos foram considerados editais no período de 2012 a 2020; e para os dados sociodemográficos, resgatou-se o período de 2012 a 2020, com as publicações do Ministério da Saúde. Como resultado, observa-se que as ações, políticas públicas e regulatórias contribuíram para a expansão dos programas de plantas medicinais e fitoterapia pelo Brasil, e das Farmácias Vivas no âmbito do SUS. Concluiu-se que os recursos financeiros foram disponibilizados com regularidade e destinação específica, porém distribuindo-se de forma desigual, considerando as necessidades sociodemográficas regionais. Seria necessário maior aporte financeiro para as regiões de maior fragilidade socioeconômica, a desburocratização dos trâmites para acesso aos recursos, e o fortalecimento das políticas públicas regionais.
\end{abstract}

Palavras-chave: Plantas Medicinais; Fitoterapia; Política de saúde; Assistência farmacêutica; Atenção Primária à Saúde; Farmácias vivas.

\begin{abstract}
The aim of this study was to analyze the implementation of the National Policy on Medicinal Plants and Herbal Medicines in the Brazilian Unified Health System through Live Pharmacies. The methodology consists of a descriptive documental and bibliographic research, based on a search for journal articles, books, survey of official normative documents, in databases such as the Capes/MEC Journal Portal, PubMed, Scielo, Academic Google, Ministry of Health portal, Official Gazette of the Union, official website of the health secretariats, Anvisa and IBGE. In the period between March 2020 and October 2020. For a survey of actions, public and regulatory policies in the scope of medicinal and herbal plants, regulations were sought between 1982 and 2009. The period from 1983 to 2020 was considered for analysis of the institutionalization of Living Pharmacies. In relation to public resources, notices were considered in the period from 2012 to 2020; and for sociodemographic data, the period from 2012 to 2020 was retrieved, with the publications of the Ministry of Health. As a result, it is observed that actions, public and regulatory policies contributed to the expansion of medicinal plants and phytotherapy programs by the Brazil, and the Live Pharmacies within the scope of the SUS. It was concluded that the financial resources were made available with regularity and specific destination, but distributed unevenly, considering the regional sociodemographic needs. Greater financial support would be needed for regions with greater socio-economic vulnerability, reducing bureaucracy in accessing resources, and strengthening regional public policies.
\end{abstract}

Keywords: Medicinal plants; Phytotherapy; Health policy; Pharmaceutical care; Primary Health Care; Live pharmacies. 


\begin{abstract}
Resumen
El objetivo de este estudio fue analizar la implementación de la Política Nacional de Plantas Medicinales y Fitosanitarios en el Sistema Único de Salud de Brasil a través de Farmacias Vivas. La metodología consiste en una investigación descriptiva documental y bibliográfica, basada en una búsqueda de artículos de revistas, libros, relevamiento de documentos normativos oficiales, en bases de datos como el Portal de Revistas Capes / MEC, PubMed, Scielo, Google Académico, portal del Ministerio de Salud, Boletín Oficial de la Unión, sitio web oficial de las secretarías de salud, Anvisa e IBGE. En el período comprendido entre marzo de 2020 y octubre de 2020. Para un relevamiento de acciones, políticas públicas y regulatorias en el ámbito de las plantas medicinales y herbales, se buscó reglamentación entre 1982 y 2009. Se consideró el período de 1983 a 2020 para el análisis de la institucionalización de Farmacias Vivas. En relación a los recursos públicos, se consideraron las notificaciones en el período de 2012 a 2020; y para datos sociodemográficos, se recuperó el período de 2012 a 2020, con las publicaciones del Ministerio de Salud. Como resultado, se observa que acciones, políticas públicas y regulatorias contribuyeron a la expansión de plantas medicinales y programas de fitoterapia por parte de Brasil, y las Farmacias Vivas en el ámbito del SUS. Se concluyó que los recursos financieros se dispusieron con regularidad y destino específico, pero distribuidos de manera desigual, considerando las necesidades sociodemográficas regionales. Se necesitaría un mayor apoyo financiero para las regiones de mayor debilidad socioeconómica, menor burocracia en el acceso a los recursos y fortalecimiento de las políticas públicas regionales.
\end{abstract}

Palabras clave: Plantas medicinales; Fitoterapia; Política de salud; Cuidado farmacéutico; Atención Primaria de Salud; Farmacias vivas.

\title{
1. Introdução
}

De acordo com a Organização Mundial da Saúde (OMS), entre $65 \%$ e $80 \%$ da população mundial usam plantas medicinais na atenção primária à saúde (WHO, 2011). A utilização dessas plantas tem crescido no mercado global de medicamentos; a comercialização de fitofármacos gira em torno de 115 milhões de dólares anuais (Ichim et al., 2020). Atribui-se esse crescimento ao aumento da demanda por produtos naturais, à conscientização sobre a saúde preventiva e ao aumento dos gastos com saúde e bem-estar (GMR, 2020). Conforme o Relatório Global da OMS sobre medicina tradicional e complementar, o interesse por plantas medicinais e fitoterápicos aumentou significativamente em países cujos programas nacionais e agências regulatórias reconhecem o uso da medicina tradicional e complementar em seus sistemas de saúde (OMS, 2019).

A OMS tem estratégias para a implementação global da medicina tradicional e complementar, estabelecendo regras norteadoras e monografias das espécies vegetais, mas sugere que cada Estado-Membro elabore suas regulamentações (WHO, 2019). A União Europeia, por exemplo, segue as normas do Comitê de Medicamentos à Base de Plantas (EMA, 2021) e Farmacopeia Europeia (Council of Europe, 2019). Nos Estados Unidos, produtos à base de plantas são controlados tanto como medicamentos quanto como suplementos alimentares pela Administração de Alimentos e Medicamentos (FDA, 2021) e Farmacopeia Americana (USP, 2021). Assim como outros Estados-Membros da OMS, o Brasil regulamentou a utilização de plantas medicinais por meio da Política Nacional de Práticas Integrativas e Complementares (PNPIC) (Brasil, 2006a) e da Política Nacional de Plantas Medicinais e Fitoterápicos (PNPMF), que visam a garantir acesso seguro e uso racional de plantas medicinais e fitoterápicos, além do desenvolvimento de tecnologias e inovações (Brasil, 2006b). Em 2009, foi publicada a Relação Nacional de Plantas Medicinais de Interesse ao Sistema Único de Saúde - SUS (RENISUS), para orientar estudos e pesquisas que possam subsidiar a elaboração da relação de fitoterápicos disponíveis para uso da população com segurança e eficácia (Brasil, 2009a). Para promover o acesso, a distribuição na rede pública de saúde, a produção segundo técnicas farmacêuticas e a orientação de consumo com apoio técnico-científico, instituiu-se o Programa Farmácias Vivas no âmbito do SUS em 2010. O Programa compreende as etapas de cultivo, coleta, processamento, armazenamento, manipulação e dispensação de preparações magistrais e oficinais de plantas medicinais e fitoterápicos, a partir de espécies vegetais com certificação botânica (Brasil, 2010).

Apesar de a PNPMF (Brasil, 2006b) ter contribuído para o crescimento dos programas de plantas medicinais (Ribeiro, 2019), o Brasil ainda apresenta problemas na consolidação da fitoterapia no SUS (Antonio et al., 2014) e na estruturação e funcionamento adequado das Farmácias Vivas (FV). Embora existam problemas de déficit de recursos financeiros e falta de apoio de gestores para investimentos em infraestrutura, compra de equipamentos e insumos vegetais (Antonio et al., 2014), além de 
excesso de burocracia na execução de recursos, quando disponíveis (Ferreira et al, 2017), não existem pesquisas relacionando toda essa problemática com fatores sociodemográficos. Segundo Nascimento et al., deve-se considerar como o cenário sociodemográfico das regiões brasileiras, com suas diferenças, afeta o acesso à saúde. De fato, existem discrepâncias de cerca de 62,5\% quanto à disponibilidade de medicamentos alopáticos na atenção básica do SUS, enquanto a disponibilidade de fitoterápicos varia em torno de 0,8 a 8,6\%, quando consideradas as cinco regiões brasileiras (Nascimento et al., 2017). Diante do exposto, o objetivo deste artigo foi realizar um levantamento das ações e políticas públicas e regulatórias no contexto de plantas medicinais e fitoterápicos e recursos públicos que contribuíram para o desenvolvimento das Farmácias Vivas, relacionando esses dados com aspectos sociodemográficos regionais.

\section{Metodologia}

Para a realização deste trabalho, foi desenvolvido um estudo descritivo, baseado em um levantamento normativo e bibliográfico entre março de 2020 e outubro de 2021. A coleta de dados foi realizada acessando as bases de dados e buscando-se artigos e documentos sobre fitoterapia, plantas medicinais e as Farmácias Vivas. Como estratégia de busca foram utilizadas as palavras-chaves ou descritores: "Farmácias Vivas", "Plantas Medicinais", "Fitoterápicos", "Plantas Medicinais e Fitoterápicos", "Fitoterapia", "Atenção Primária à Saúde", "Serviços de Saúde". Para fundamentar a análise de dados, o material foi selecionado e categorizado utilizando linhas temporais, a partir da sua relação com os objetivos específicos. Na apresentação dos dados e das análises, foram utilizados quadros e figuras a partir de gráficos e tabelas elaboradas com as informações levantadas.

Para a coleta de dados sobre ações, políticas públicas e regulatórias, realizou-se uma busca por artigos de periódicos, livros, levantamento de documentos normativos oficiais, em bases de dados como o Portal de Periódicos Capes/MEC, PubMed, Scielo, Google Acadêmico, portal do Ministério da Saúde, Diário Oficial da União e site oficiais das secretarias de saúde de estados e prefeituras. Esses documentos foram analisados segundo ano de publicação, origem e conteúdo, resgatando o processo histórico de ações e políticas de plantas medicinais e fitoterápicos no Brasil. Foram incluídos os documentos que discorreram sobre o processo histórico do uso das plantas medicinais; o desenvolvimento dos estudos e da ciência dos fitoterápicos no Brasil; o resgate e as menções sobre práticas integrativas e complementares pelos órgãos internacionais e nacionais e do reconhecimento e prática da fitoterapia pelos conselhos profissionais. O recorte temporal deu-se a partir de 1982, com a criação do Programa de Pesquisa de Plantas Medicinais da CEME, até 2009, com a criação da Relação Nacional de Plantas Medicinais de Interesse ao SUS (RENISUS).

Para a coleta dos documentos relacionados à institucionalização das farmácias vivas foram buscadas normativas do governo federal e da Anvisa, disponíveis no portal do Ministério da Saúde e Diário Oficial da União, bem como artigos de periódicos pesquisados no Portal de Periódicos Capes/MEC, PubMed, Scielo e Google Acadêmico, relativos à criação e à institucionalização das Farmácias Vivas no âmbito do SUS; exemplos de Farmácias Vivas já implantadas no país e as experiências compartilhadas; exemplos da integração dessas políticas no SUS pelo uso das plantas medicinais e fitoterápicos produzidos pelas Farmácias Vivas, relatando à criação e à institucionalização das Farmácias Vivas no âmbito do SUS; exemplos de Farmácias Vivas já em desenvolvimento e o crescimento do número de Farmácias Vivas no Brasil. Foram compreendidos os anos entre os anos de 1983, ano de criação do Projeto Farmácias Vivas, e 2020, ano em que, até então, encontramos publicações que fazem menção ao tema.

Para coletar as informações sobre os recursos disponibilizados pelo Ministério da Saúde ao desenvolvimento das Farmácias Vivas e da participação dos estados e municípios brasileiros, foram considerados os editais e portarias publicados no Diário Oficial da União e página oficial do Ministério da Saúde, observando o ano de publicação, os valores propostos e/ou aprovados, qual a destinação dos recursos, os estados e municípios participantes e o recurso aprovado para cada um deles, identificando se houve progresso nos programas de fitoterapia. Foram considerados documentos datados do período de 2012 a 
2020. O recorte temporal deu-se por ser o período de publicações que o Ministério da Saúde dispensou recursos no âmbito da PNPMF. Os dados foram organizados e apresentados na forma de tabelas e gráficos, elaborados no Origin versão 8.1 (OriginLab Corporation, Northampton, MA, USA).

Foram coletados dados sociodemográficos relativos ao número populacional e renda per capita de brasileiros dos 26 estados brasileiros e Distrito Federal na página oficial do IBGE. Foi feito um levantamento da distribuição dos recursos entre os estados e regiões brasileiras, comparando esses investimentos com os dados sociodemográficos de cada região, considerando o período de 2012 a 2020, anos das publicações do MS que destinaram os recursos à PNPMF.

\section{Resultados}

Antes da institucionalização das Farmácia Viva no âmbito do SUS, o uso de plantas medicinais e fitoterápicos já era praticado no Brasil. As ações no contexto de plantas medicinais tiveram início na década de 80 , sobretudo após a criação do Programa de Pesquisa de Plantas Medicinais da Central de Medicamentos, em 1982, e do Projeto Farmácias Vivas, vinculado à Universidade Federal do Ceará, em 1983 (Brasil, 2006a). Tal Projeto levou à promulgação da Política Estadual de Fitoterapia em Saúde Pública no Ceará, em 1999, implantando unidades de Farmácia Viva na rede pública de saúde e servindo como modelo para o restante do país (Sá, 2016).

Em decorrência da expansão do uso de plantas medicinais e fitoterápicos pelo Brasil, a Anvisa, enquanto agência reguladora, expediu normativas para identificar e organizar o registro das plantas medicinais e fitoterápicos (Brasil, 1994), guias e listas de fitoterápicos (Brasil, 2014a), estudos de toxicidade (Brasil, 2004a), bem como normas de processamento, armazenamento, preparação e dispensação das plantas medicinais e fitoterápicos (Brasil, 2013a) nas Farmácia Viva existentes (Brasil, 2006a).

Por ação de interesse popular e institucional pelos fitoterápicos, e ainda para regulamentar o seu uso (Balbino \& Dias, 2010), expandir as opções terapêuticas disponíveis para melhorar a atenção à saúde aos usuários do SUS e entrar em consonância com as recomendações da OMS (WHO, 2013), foi aprovada a PNPIC (Brasil, 2006a). A Política passou a contemplar, entre outras coisas, diretrizes para a implantação ou adequação de ações e serviços de plantas medicinais e fitoterapia no Brasil, baseando sua elaboração na PNPMF (Brasil, 2006b). Assim, a PNPIC e a PNPMF representam os principais marcos regulatórios do reconhecimento da importância das plantas medicinais e da valorização dos fitoterápicos no Brasil.

Em 2009, foi publicada a Relação Nacional de Plantas Medicinais de Interesse ao SUS (RENISUS) (Brasil, 2009a), com a finalidade de orientar estudos e pesquisas a fim de contribuir para a elaboração da relação de fitoterápicos disponíveis para o uso seguro pela população, sendo posteriormente incluídos na RENAME, que lista os medicamentos disponibilizados pelo SUS.

No contexto da PNPMF (Brasil, 2006b) e da Política de Assistência Farmacêutica (Brasil, 2004b), a Farmácia Viva é o programa do SUS responsável pelo cultivo, preparação e dispensação de plantas medicinais na forma de planta fresca (in natura), planta seca (droga vegetal) e fitoterápicos manipulados (Brasil, 2010). Mas é notável que o reflexo das ações das Farmácias Vivas está além dos benefícios à Saúde Pública, com a disponibilização de fitoterápicos à população, pois ela contribui para a promoção do uso sustentável da biodiversidade, o desenvolvimento da cadeia produtiva e da indústria nacional, a sustentabilidade socioeconômica e a preservação e valorização do conhecimento tradicional e popular sobre o uso de plantas medicinais (Randal et al., 2016).

Após sua criação, em 1983, porém, o Programa Farmácias Vivas somente foi institucionalizado no âmbito do SUS em 2010, por meio da Portaria n. 886/2010 (Brasil, 2010). A partir de então houve o crescimento dos programas municipais de fitoterapia, demonstrando um aumento acentuado, passando de 116 municípios que continham programas em 2004 para $346 \mathrm{em}$ 2008, 815 em 2012 (Ribeiro, 2019) e 900 em 2016, ofertando medicamentos fitoterápicos industrializados, manipulados, drogas vegetais e planta medicinal fresca no SUS (Brasil, 2021). 
Constatamos então que, como reflexo da PNPMF, diferentes ações e políticas públicas continuaram sendo executadas em âmbito nacional, no sentido de promover o uso das plantas medicinais e fitoterápicos e estruturar as Farmácia Viva na rede pública, principalmente na Atenção Primária à Saúde (Quadro 1). Dentre essas ações, podemos destacar a publicação do Formulário de Fitoterápicos da Farmacopeia Brasileira (Brasil, 2011), da Portaria MS n. 1.555/2013, que dispôs sobre as normas de financiamento e execução do Componente Básico da Assistência Farmacêutica, e da atualização da RENAME, com a inclusão de 12 fitoterápicos (Brasil, 2013c). Foi publicado também o Memento Fitoterápico (Brasil, 2016) e a Portaria MS n. 5/2017 (Brasil, 2017), que consolidou as normas sobre as ações e os serviços de saúde do SUS.

Quadro 1 - Linha do tempo de ações e políticas públicas e regulamentares que promoveram o uso de plantas medicinais, fitoterápicos e a implementação de Farmácias Vivas no Brasil (2010-2020).

\begin{tabular}{|c|c|c|}
\hline Ano & Documento oficial & Objetivo \\
\hline 2010 & Portaria MS n. 886/2010 & Institucionalizou a Farmácia Viva no âmbito do SUS. \\
\hline 2011 & $\begin{array}{l}\text { Formulário de Fitoterápicos da } \\
\text { Farmacopeia Brasileira (RDC } \\
\text { MS/Anvisa n. 60/2011) }\end{array}$ & $\begin{array}{l}\text { Publicada a } 1^{\text {a }} \text { edição. Voltou-se principalmente às práticas de manipulação e dispensação de } \\
\text { fitoterápicos, contribuindo com os Serviços de Fitoterapia e Farmácias Vivas existentes em } \\
\text { todo o país. }\end{array}$ \\
\hline 2011 & Portaria MS/SAS n. 470/2011 & $\begin{array}{l}\text { Incluiu na tabela de serviços/classificação do Sistema de Cadastro Nacional de } \\
\text { Estabelecimentos de Saúde - SCNES, no serviço de código } 125 \text { - Serviço de Farmácia, a } \\
\text { classificação } 007 \text { - Farmácia Viva. }\end{array}$ \\
\hline 2013 & RDC MS/Anvisa n. 18/2013 & $\begin{array}{l}\text { Dispôs sobre as boas práticas de processamento e armazenamento de plantas medicinais, } \\
\text { preparação e dispensação de produtos magistrais e oficinais de plantas medicinais e } \\
\text { fitoterápicos em Farmácias Vivas. }\end{array}$ \\
\hline 2013 & Portaria MS n. 1.555/2013 & $\begin{array}{l}\text { Dispôs sobre as normas de financiamento e de execução do Componente Básico da } \\
\text { Assistência Farmacêutica no âmbito do SUS. }\end{array}$ \\
\hline 2013 & RDC MS/Anvisa n. 13/2013 & Dispôs sobre as boas práticas de fabricação de produtos tradicionais fitoterápicos. \\
\hline 2014 & RDC MS/Anvisa n. 26/2014 & $\begin{array}{l}\text { Criou a classe de Produto Tradicional Fitoterápico e dispôs sobre o registro de medicamentos } \\
\text { fitoterápicos e o registro e a notificação de produtos tradicionais fitoterápicos. }\end{array}$ \\
\hline 2014 & $\begin{array}{l}\text { Instrução Normativa } \\
\text { MS/Anvisa n. 02/2014 }\end{array}$ & $\begin{array}{l}\text { Publicou a "Lista de medicamentos fitoterápicos de registro simplificado" e a "Lista de } \\
\text { produtos tradicionais fitoterápicos de registro simplificado". }\end{array}$ \\
\hline 2015 & $\begin{array}{l}9^{a} \text { edição da RENAME } \\
\text { (Portaria MS/GM n. 1/2015) }\end{array}$ & $\begin{array}{l}\text { Atualizou o elenco de medicamentos e insumos da Relação Nacional de Medicamentos } \\
\text { Essenciais (RENAME), com a inclusão de } 12 \text { plantas medicinais para a preparação de } \\
\text { fitoterápicos. }\end{array}$ \\
\hline 2015 & $2^{\mathrm{a}}$ edição da PNPIC & $\begin{array}{l}\text { Publicou a } 2^{\mathrm{a}} \text { edição da Política Nacional de Práticas Integrativas e Complementares no SUS. } \\
\text { Atitude de ampliação de acesso. }\end{array}$ \\
\hline 2016 & $\begin{array}{l}1^{\text {a }} \text { edição do Memento de } \\
\text { Fitoterápicos da Farmacopeia } \\
\text { Brasileira }\end{array}$ & $\begin{array}{l}\text { Elaborou documento para consulta rápida, que visa orientar a conduta terapêutica dos } \\
\text { profissionais prescritores. }\end{array}$ \\
\hline 2017 & $\begin{array}{l}\text { Portaria de Consolidação MS } \\
\text { n. } 5 / 2017\end{array}$ & $\begin{array}{l}\text { Consolidou as normas sobre as ações e os serviços de saúde do SUS. Instituiu a formação do } \\
\text { Grupo Executivo para o PNPMF com diferentes representantes estratégicos e instituiu a } \\
\text { Farmácia Viva no âmbito do SUS. }\end{array}$ \\
\hline 2019 & $\begin{array}{l}\text { Instrução Normativa } \\
\text { MS/Anvisa n. 39/2019. }\end{array}$ & Dispôs sobre as boas práticas de fabricação complementares a medicamentos fitoterápicos. \\
\hline 2020 & $\begin{array}{l}2^{\mathrm{a}} \text { edição do Formulário de } \\
\text { Fitoterápicos da Farmacopeia } \\
\text { Brasileira (aprovada pela RDC } \\
\text { MS/Anvisa n. 463/2021) }\end{array}$ & Atualizou o formulário, contendo monografias de mais de 80 espécies vegetais. \\
\hline
\end{tabular}

RDC: Resolução da Diretoria Colegiada da ANVISA; MS: Ministério da Saúde; SUS: Sistema Único de Saúde; PNPMF: Política Nacional de Plantas Medicinais e Fitoterápicos.

É importante destacar que, nos últimos nove anos, houve investimentos em fitoterapia no âmbito do SUS que contribuíram para o desenvolvimento das Farmácias Vivas. O MS, a partir de 2012, publicou 20 documentos oficiais (editais e portarias) no intuito de fomentar projetos para apoio à Assistência Farmacêutica em Plantas Medicinais e Fitoterápicos (AF em PMF) e Arranjos Produtivos Locais (APLs), desenvolvimento e registro sanitário de medicamentos fitoterápicos, aquisição de 
equipamentos, extensão universitária e estruturação de Farmácia Viva. O objetivo consistiu em garantir aos usuários do SUS o acesso a fitoterápicos e transformar o contexto de saúde das localidades participantes.

$\mathrm{Na}$ Tabela 1, apresentamos em ordem cronológica os documentos oficiais que disponibilizaram recursos financeiros, no período de 2012 a 2020, destinados às Secretarias de Saúde Municipais (SMS), Estaduais (SES) e do Distrito Federal, em articulação com instituições, entidades e/ou empresas parceiras, laboratórios e universidades.

Tabela 1 - Lista de documentos oficiais publicados pelo Ministério da Saúde, com disponibilização de recursos financeiros para projetos de plantas medicinais e fitoterápicos no período de 2012 a 2020.

\begin{tabular}{ccl}
$\begin{array}{c}\text { Documentos } \\
\text { oficiais }\end{array}$ & $\begin{array}{c}\text { Valor total } \\
\text { proposto (R\$) }\end{array}$ & \multicolumn{1}{c}{ Destinação } \\
$\begin{array}{c}\text { Portaria MS n. } \\
15, \text { de }\end{array}$ & $3.489 .608,00$ & $\begin{array}{l}\text { I }- \text { Aquisição de equipamentos e material permanente, } \\
\text { destinados ao suporte das ações do APL; }\end{array}$ \\
$28 / 06 / 2012$ & II - Contratação de serviços de terceiros; aquisição de \\
& materiais de consumo; promoção da interação e a \\
& cooperação entre os agentes produtivos da cadeia \\
produtiva de plantas medicinais e fitoterápicos; \\
desenvolvimento da produção de plantas medicinais, \\
insumos de origem vegetal e fitoterápicos; fortalecimento \\
de laboratórios públicos ou parcerias público-privadas; \\
implantação e/ou implementação de programas e projetos \\
para a produção e dispensação de plantas medicinais e \\
fitoterápicos; qualificação técnica dos profissionais \\
envolvidos na produção e uso de plantas medicinais e \\
fitoterápicos; articulação entre políticas públicas \\
transversais e o PNPMF.
\end{tabular}

Edital
SCTIE/MS n. 1,
de
6/4/2012 (Portar
ia SCTIE/MS n.
13, de
19/06/2012)

Edital $12.000 .000,00$

SCTIE/MS n. 1

de $24 / 5 / 2013$

(Portaria

SCTIE/MS n

$2.461 \mathrm{de}$

$22 / 10 / 2013)$

\section{$6.639 .620,09$}

5.807.998,00 - Recurso de custeio

831.622,09 - Recurso de capital destinados ao suporte das ações do APL;

II - Contratação de serviços de terceiros; aquisição de materiais de consumo; promoção da interação e a cooperação entre os agentes produtivos da cadeia produtiva de plantas medicinais e fitoterápicos; desenvolvimento da produção de plantas medicinais, insumos de origem vegetal e fitoterápicos; fortalecimento de laboratórios públicos ou parcerias público-privadas; implantação e/ou implementação de programas e projetos para a produção e dispensação de plantas medicinais e fitoterápicos; qualificação técnica dos profissionais envolvidos na produção e uso de plantas medicinais e fitoterápicos; articulação entre políticas públicas transversais e o PNPMF.
I - Aquisição de equipamentos e material permanente,

6.159.565,90 - Destinado à seleção de projetos de APL,

\begin{tabular}{|cll}
$\begin{array}{c}\text { Secretaria Municipal } \\
\text { de Saúde (SMS) / } \\
\text { Secretaria Estadual de } \\
\text { Saúde (SES) }\end{array}$ & $\begin{array}{c}\text { Valor } \\
\text { aprovado (R\$) }\end{array}$ & $\begin{array}{c}\text { Total aprovado por } \\
\text { Estado em cada } \\
\text { edital (R\$) }\end{array}$ \\
$\begin{array}{c}\text { Alagoas (SES) } \\
\text { Rio Grande do Sul (SES) }\end{array}$ & $1.304 .491,00$ & AL $1.304 .491,00 \quad$ RS \\
& $2.185 .187,00$ & $2.185 .187,00$ \\
& & Total geral: \\
& & $3.489 .678,00$
\end{tabular}

Betim, MG (SMS)

$658.882,70$

MG 892.892,70

SP $706.030,00$

João Monlevade, MG
(SMS) $\quad 234.010,00$

Botucatu, SP (SMS) $\quad 352.320,00$

Itapeva, SP (SMS) $\quad 353.710,00$

Petrópolis, RJ (SMS)

Rio de Janeiro, RJ

(SMS)

Santarém, PR (SMS)

Foz do Iguaçu, PR

(SMS)

Pato Bragado, PR (SMS)

Toledo, PR (SMS)

Brejo da Madre de Deus,

PE (SMS)

Diorama, GO (SMS)

$299.195,00$

PR 2.192.762,79

PE 677.173,60

GO $812.566,00$

Total geral:

$1.059 .000,00$

6.639.620,09

$127.679,00$

$939.557,32$

$521.741,04$

$603.785,43$

$677.173,60$

$812.566,00$

Ceará (SES)

$980.654,40$ compreendidos como os diversos tipos de aglomerações produtivas, envolvendo diferentes segmentos de atores: empresas (produtoras, fornecedoras, prestadoras de serviços, comercializadoras), instituições públicas e privadas voltadas para formação de recursos humanos, pesquisa e desenvolvimento, apoio e financiamento, que atuam de forma interdependente.
João Pessoa, PB (SMS)

Ipatinga, MG (SMS)

Uberlândia, MG (SMS)

Niterói, RJ (SMS)

Poconé, MT (SMS)

São Lourenço do Sul, RS (SMS)

Distrito Federal (SES)
Iguatemi, MS (SMS)

$605.536,37$

475.916 .75

$504.370,99$

$668.839,51$

$928.765,31$

$977.208,84$

$791.875,00$

226.398,73

$55.000,00$

$305.000,00$

$305.000,00$ apoio à estruturação e ao fortalecimento da AF em PMF Qualifar-SUS

\section{Acre (SES)}

Espírito Santo (SES)

Goiás (SES)

Bom Jesus, PI (SMS)

Catas Altas, MG (SMS)

Coruripe, AL (SMS)

Florianópolis, SC (SMS)

Frutuoso Gomes, RN

\section{$75.000,00$}

$155.000,00$
MG 1.173.210,50

CE 980.654,40

PB 605.536,37

MS 475.916.75

RJ 928.765,31

MT 977.208,84

RS 791.875,00

DF 226.398,73

Total geral:

6.159.565,90

AC 385.000,00

ES $305.000,00$

GO 305.000,00

PI 95.000,00

MG 575.000,00

AL 20.000,00

SC $225.000,00$

RN 15.000,00 


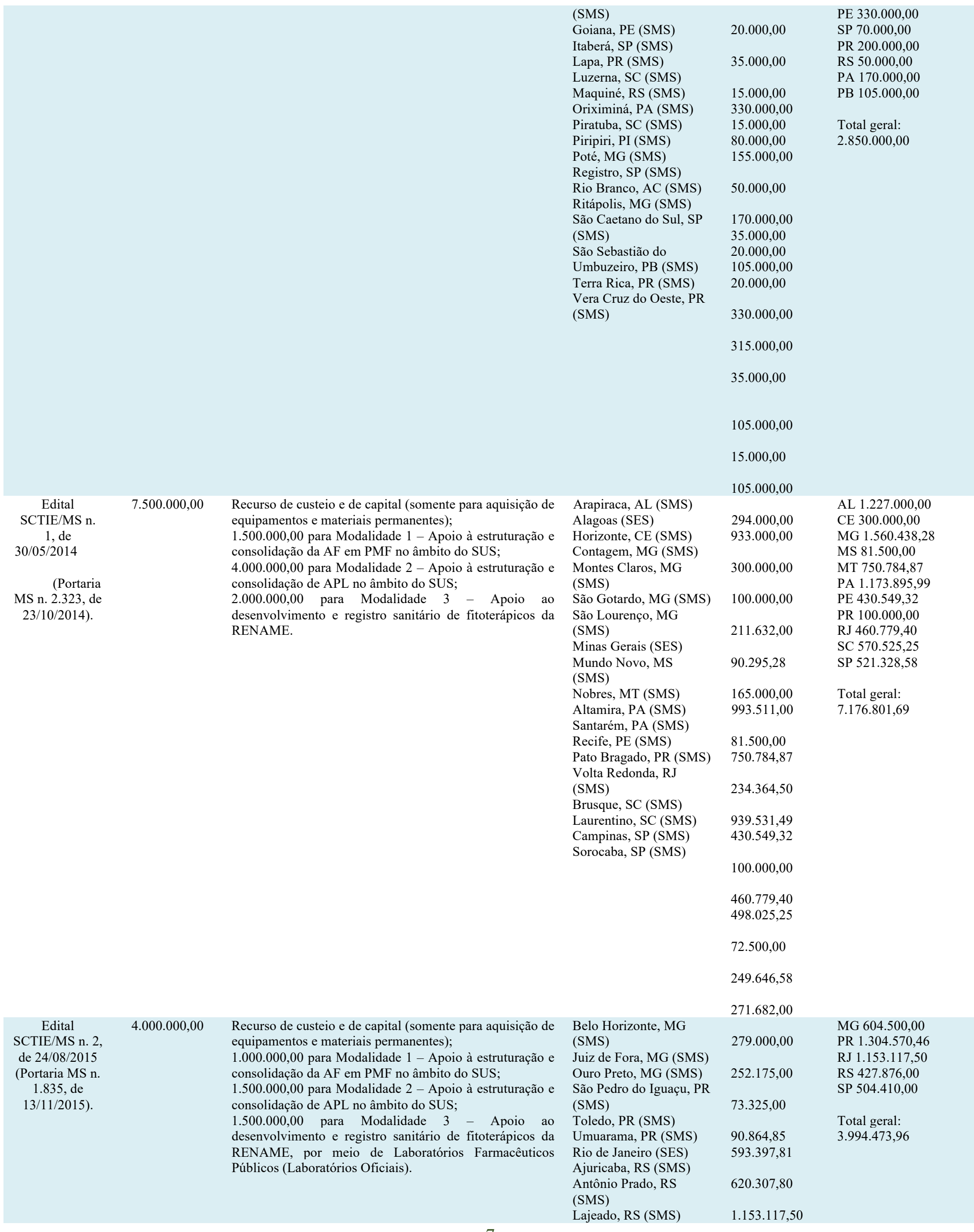




\begin{tabular}{|c|c|c|}
\hline $\begin{array}{c}\text { Portaria MS n. } \\
1.850, \mathrm{de} \\
13 / 10 / 2016\end{array}$ & $1.064 .214,00$ & $\begin{array}{l}\text { Repasse para desenvolver projetos de } \mathrm{AF} \text { em PMF na } \\
\text { Região Norte do Brasil. }\end{array}$ \\
\hline $\begin{array}{l}\text { Chamada } \\
\text { pública SCTIE- } \\
\text { MS n. } 1 \text { de } \\
\text { 16/11/2017 } \\
\text { (Portaria MS n. } \\
\text { 3.483, de } \\
\text { 18/12/2017). }\end{array}$ & $7.000 .000,00$ & $\begin{array}{l}80 \% \text { como recurso de custeio; } \\
20 \% \text { como recurso de capital; } \\
\text { Objetivo é selecionar propostas para apoio financeiro a } \\
\text { projetos de estruturação de FARMÁCIA VIVA ou de } \\
\text { farmácia com manipulação de fitoterápicos, no âmbito da } \\
\text { extensão universitária, a partir de parceria entre } \\
\text { Secretarias de Saúde e Instituições de Ensino Superior } \\
\text { (IES). }\end{array}$ \\
\hline
\end{tabular}

\section{Lauro de Freitas, BA \\ (SMS)}

Governador Valadares, MG (SMS)

Itanhandu, MG (SMS)

Teresina, PI (SES)

Francisco Beltrão, PR

(SMS)

Itajaí, SC (SMS)

Jardinópolis, SP (SMS)

Ribeirão Preto, SP

(SMS)

São Caetano do Sul, SP

(SMS)

Palmas, TO (SES)

Quixeré, CE (SMS)
Alfenas, MG (SMS)
Betim, MG (SMS)
Vitória de Santo Antão,
PE (SMS)
Gramado, RS (SMS)
Nova Petrópolis, RS
(SMS)
Gaspar, SC (SMS)
Santa Rosa de Lima, SC
(SMS)
Carmópolis, SE (SMS)
Cruzeiro, SP (SMS)
Piacatu, SP (SMS)

Edital

4.283.325,00

SCTIE/MS n. 1,

de 5 de

novembro de

2018 (Portaria

MS n. 3.862, de

5/12/2018).
Recurso de custeio e de capital (somente para aquisição de equipamentos e materiais permanentes);

Seleção de projetos de estruturação e consolidação de AF em PMF, com ênfase em controle de qualidade, contribuindo para garantir o acesso de usuários do SUS a fitoterápicos com qualidade, segurança e eficácia, conforme a PNPMF.

\section{Edital de}

chamada

pública

SCTIE/MS n. 2,

de 13/06/2019

(Portaria MS n.

2.768 , de

$21 / 10 / 2019)$
8.060.000,00 Recurso de custeio e de capital (somente para aquisição de equipamentos e materiais permanentes);

Seleção de projetos de estruturação e consolidação de $\mathrm{AF}$ em PMF, com ênfase em controle de qualidade, contribuindo para garantir o acesso de usuários do SUS a fitoterápicos com qualidade, segurança e eficácia, conforme a PNPMF.
Santo Ângelo, RS (SMS)

Brasiléia, AC (SMS)

Manaus, AM (SMS)

Amapá (SES)

Abaetetuba, PA (SMS)

Colinas do Tocantins,

TO (SMS)
Itapeva, SP (SMS)

$\begin{array}{ll}56.580,00 & \\ 80.446,00 & \\ 225.300,00 & \\ & \\ 65.550,00 & \\ 504.410,00 & \text { Total geral: } \\ 87.000,00 & 1.064 .214,00 \\ & \\ 314.614,00 & \\ 209.100,00 & \\ & \\ & \end{array}$

$113.500,00$

$340.000,00$

$312.837,15$

MG $1.146 .750,89$

PI $171.500,00$

PR $705.015,20$

SC $595.794,60$

$938.750,89$

SP $970.866,13$

$208.000,00$

$171.500,00$

$705.015,20$

TO 446.236,02

Total geral:

$595.794,60$

4.349.000,00

$596.062,58$

$239.303,55$

$135.500,00$

$446.236,02$

$354.226,52$

$391.200,52$

$499.400,00$

$358.923,52$

$500.000,00$

$420.506,82$

$458.593,52$

$292.093,52$

$372.393,52$

$339.693,52$

296.293,52

São Miguel dos Campos, AL (SMS)

Crato, CE (SMS)

Limoeiro do Norte, CE

(SMS)

Cidade Ocidental, GO

(SMS)

Niquelândia, GO (SMS)

Amarante do Maranhão,

MA (SMS)

Governador Edison

Lobão, MA (SMS)

Itajubá, MG (SMS)

São Gotardo, MG (SMS)

Sousa, PB (SMS)

Quissamã, RJ (SMS)

Capão Bonito do Sul, RS

(SMS)

Farroupilha, RS (SMS)

Pontão, RS (SMS)

São Leopoldo, RS

(SMS)

Balneário Camboriú, $\mathrm{SC}$

(SMS)

Joinville, SC (SMS)
$291.227,15$

$259.227,15$

$507.602,76$

$461.227,15$

$336.227,15$

$485.227,15$

$400.327,15$

$341.246,20$

$416.797,14$

$335.499,72$

$454.372,13$

$190.102,15$

$441.327,15$

$455.727,15$ 


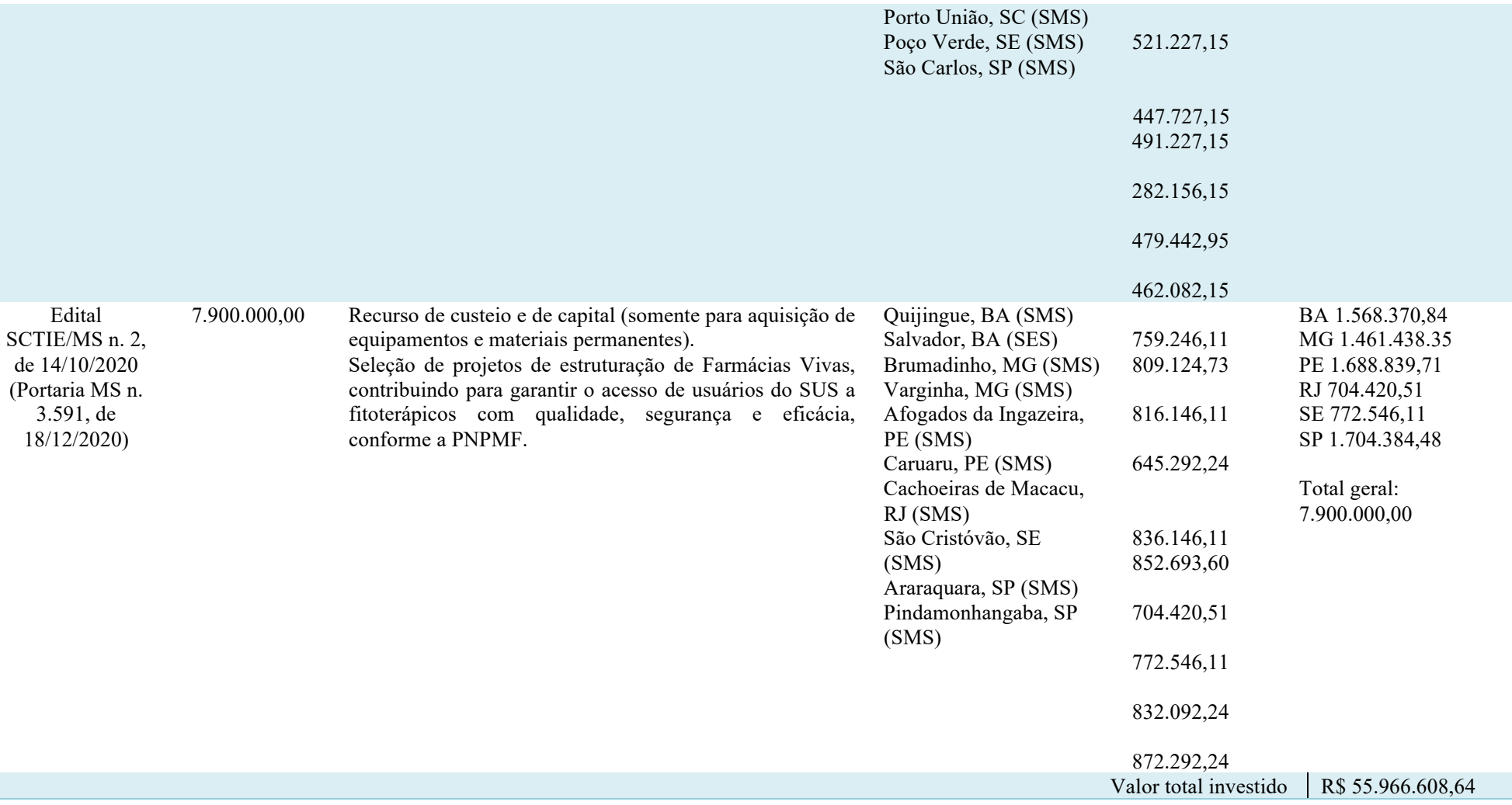

APL: Arranjos Produtivos Locais; AF em PMF: Assistência Farmacêutica em Plantas Medicinais e Fitoterápicos; PNPMF: Política Nacional de Plantas Medicinais e Fitoterápicos; SCTIE/MS: Secretaria de Ciência, Tecnologia e Insumos Estratégicos/ Ministério da Saúde; SES: Secretaria Estadual de Saúde; SMS: Secretaria Municipal de Saúde; SUS: Sistema Único de Saúde.

Fonte: Elaboração a partir de documentos oficiais do Ministério da Saúde publicados no período de 2012 a 2020.

Em 2012, o MS publicou a Portaria n. 15 e o Edital SCTIE/MS n. 1/2012, que juntos totalizaram mais de 10 milhões de reais a serem empregados, entre outras coisas, na aquisição de equipamentos, suporte às ações das APLs e qualificação técnica, destinando $100 \%$ dos recursos disponíveis para dois estados e 12 municípios. Já em 2013 destinou-se o maior montante $(\mathrm{R} \$ 12.000 .000,00)$ já proposto nos últimos nove anos para apoio às APLs. Porém, apenas 47\% desse recurso disponível foi aprovado e repassado a municípios das regiões Nordeste, Sudeste, Centro-Oeste e Sul. Por fim, o Edital SCTIE/MS n. 1/2012 colaborou com a estruturação e o fortalecimento da AF em PMF, contemplando 24 municípios.

Em 2014, foi disponibilizado pelo Edital SCTIE/MS n. 1/2014 o valor de R\$7.500.000,00, distribuído em três modalidades: estruturação e consolidação da AF em PMF, estruturação e consolidação da APL e desenvolvimento e registro sanitário de fitoterápicos da RENAME. Posteriormente, a Portaria MS n. 2.323/2014 aprovou o repasse de 96\% desses recursos. No Edital SCTIE/MS n. 2/2015, foi proposto um recurso de 4 milhões de reais para atender projetos nas três modalidades, contemplando o estado do Rio de Janeiro e 11 municípios do Sul e Sudeste.

Em 2016, houve um edital exclusivo para AF em PMF da região Norte do país, disponibilizando R $\$ 7.000 .000,00$, sendo 20\% desse recurso destinados ao apoio a projetos de estruturação de Farmácia Viva ou de farmácias com manipulação de fitoterápicos.

Em 2018 e 2019, os recursos totalizaram $\mathrm{R} \$ 12.343,325,00$, aprovados integralmente e aplicados em 31 municípios de 12 estados, exceto para municípios da região Norte. Em 2020, mesmo com a pandemia do novo coronavírus instaurada no país, demandando grande investimento do MS, foi publicado o Edital SCTIE/MS n. 2/2020, com a disponibilização de R\$ 7.900.000,00, Os recursos foram destinados à estruturação de Farmácia Viva, contemplando apenas municípios das regiões Nordeste e Sudeste. 
No intervalo entre 2012 e 2020, foram aprovados aproximadamente $\mathrm{R} \$ 56.000 .000,00$ em recursos que contribuíram para subsidiar a estruturação das Farmácia Viva no âmbito do SUS. Na Figura 1, é possível observar a distribuição desses recursos entre os estados brasileiros, demonstrando a maior participação das regiões Sudeste, Nordeste e Sul.

Figura 1 - Distribuição dos recursos financeiros provenientes do Ministério da Saúde para projetos de plantas medicinais e fitoterápicos no período de 2012 a 2020.

\section{Recursos aplicados à fitoterapia no âmbito do SUS (2012-2020)}

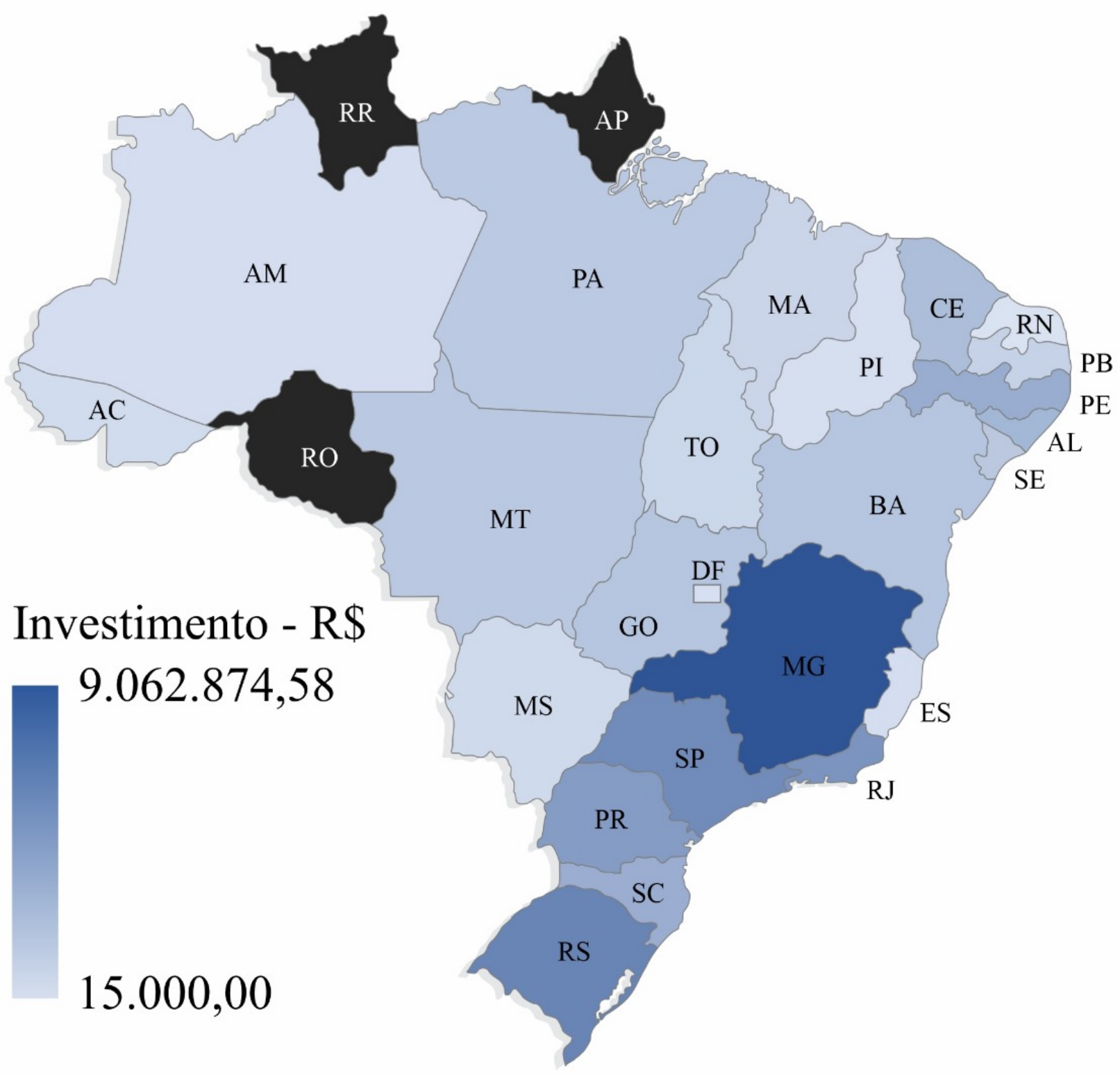

*Os estados Amapá, Rondônia e Roraima, não participaram dos editais.

Fonte: Elaboração a partir de documentos oficiais do Ministério da Saúde publicados no período de 2012 a 2020. 
É interessante destacar que vários estados do Nordeste participaram da seleção, captando recursos superiores a 1 milhão de reais, com exceção do Maranhão, Piauí e Rio Grande do Norte, sendo este o estado que recebeu o menor recurso no período estudado. Estados como Mato Grosso do Sul, Acre, Amazonas e Distrito Federal receberam valores entre 200 e 600 mil reais. Apenas três entre todos os estados brasileiros não foram contemplados com recursos do MS: Rondônia, Roraima e Amapá.

A associação das informações acerca dos recursos financeiros aplicados à fitoterapia, com os dados sociodemográficos relativos à renda per capita e à população dos estados brasileiros no período de 2012-2020 (Figura 2) permite observar que as regiões mais populosas foram as que captaram o maior percentual de recursos. Assim, o Sudeste veio em primeiro lugar, seguido do Nordeste e do Sul. A região Norte obteve o menor percentual (5,79\%) de recursos, enquanto a região Centro-Oeste apresentou a menor população média brasileira. Entretanto, as maiores rendas per capita médias nesse período, em ordem decrescente, foram encontradas no Centro-Oeste, Sul, Sudeste, Norte e Nordeste.

Figura 2 - Comparação entre o percentual arrecadado, população média e renda per capita média das cinco regiões brasileiras no período de (2012-2020).
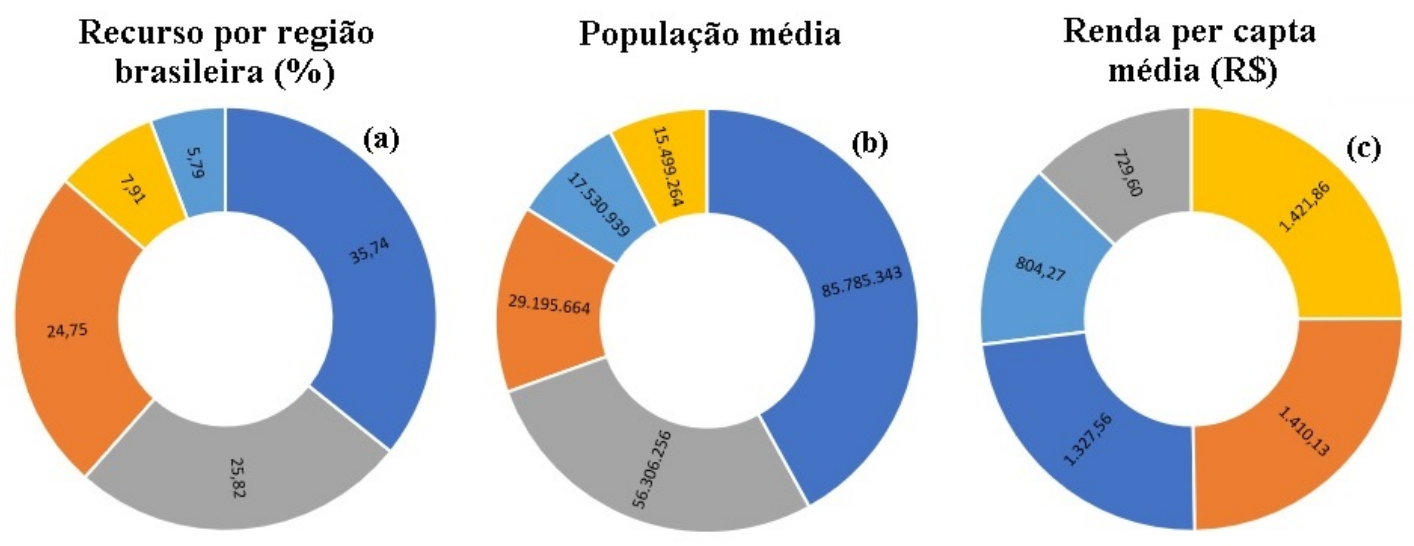

- Sudeste $\mid$ Sul $\mid$ Nordeste $\mid$ Centro-Oeste $\mid$ Norte

a) Percentual de recurso investido em fitoterapia (\%); b) população média; e c) renda per capita média (em reais). Fonte: Elaboração a partir dos dados dos Editais SCTIE/MS e dados sociodemográficos do IBGE (2012 a 2020).

\section{Discussão}

Com base no levantamento das ações e políticas públicas e regulatórias, podemos afirmar que o Brasil, nos últimos anos, tem mantido compromisso com o desenvolvimento de políticas nacionais para o uso de plantas medicinais e fitoterápicos (WHO, 2019). Dessa forma, a criação da PNPIC e da PNPMF ressignificou a Atenção Primária à Saúde e contribuiu para ampliar a assistência farmacêutica e buscar qualidade e segurança nos medicamentos de origem vegetal. A partir desses marcos regulatórios, estados e municípios criaram políticas locais e os serviços de saúde passaram a oferecer plantas medicinais e fitoterápicos, além de aumentar o número de profissionais que utilizam a fitoterapia no tratamento de seus pacientes (Figueiredo et al., 2014). De acordo com a OMS, mudanças também têm ocorrido em outros países: em 2018, 98 Estados-Membros haviam desenvolvido políticas nacionais, 109 lançado leis ou regulamentos nacionais e 124 implementado regulamentos sobre fitoterapia (WHO, 2019).

Observamos que, com as ações previstas na PNPMF, foi possível realizar a estruturação e a consolidação das Farmácias Vivas, o que possibilitou a implementação do Programa em diferentes regiões do Brasil. Houve um crescimento no número de programas municipais de fitoterapia, com aumento expressivo a partir de 2006 (Ribeiro, 2019). Quando foi lançada a PNPMF, em 2012, o Brasil apresentava cerca de 3 mil estabelecimentos de saúde com atividades de fitoterapia registradas, distribuídos por 815 
municípios. O Ceará, estado pioneiro no desenvolvimento do Programa Farmácia Viva, apresentava, em 2015, 99 registros de Farmácia Viva - dentre estas, 42,4\% em funcionamento e instaladas com vínculos governamental e não governamental (Bonfim et al., 2018; Pereira et al., 2017; Rufino et al., 2018). No Distrito Federal, segundo a Secretaria de Estado em Saúde (Brasil, 2021), estão implementadas e em funcionamento duas unidades de Farmácia Viva, que produzem os medicamentos fitoterápicos a partir de plantas cultivadas nas próprias farmácias, posteriormente distribuídos para 22 unidades básicas de saúde. Minas Gerais, no período avaliado, realizou iniciativas importantes, como a estruturação da Farmácia Viva de Betim, com a consolidação da produção da matéria-prima vegetal, controle de qualidade, dispensação e capacitação, a partir de recursos disponibilizados pelo MS (Bonfim et al., 2018; Carvalho, 2017). Em Picos, no Piauí, a Farmácia Viva foi incluída no Programa de Saúde da Família (Pereira et al., 2015). Em Vitória, no Espírito Santo, a Farmácia Viva operava articulada à comunidade e ao SUS, mas foi desativada, sendo mantida a distribuição de fitoterápicos industrializados (Magalhães, 2019).

Nossos resultados e de Ferreira et al. (2017) contrariam o que afirmam Antonio et al. (2014) quanto à carência de recursos aplicados aos programas de fitoterapia no SUS. Mesmo com recursos sendo disponibilizados a partir de 2012, porém, Ribeiro (2019), Randal et al. (2016) e Bonfim et al. (2018) relatam que o Programa Farmácia Viva necessita de financiamento específico e permanente, garantido por lei, para a expansão da fitoterapia no SUS; dessa forma possibilitaria a manutenção dos projetos e evitando a descontinuação do programa e da assistência à população, uma vez que um dos maiores problemas apontados no uso dos investimentos disponibilizados pelo MS é a burocracia para a execução desses recursos, o que acaba por atrasar a execução dos projetos, segundo Ferreira et al. (2017).

De fato, averiguamos em nosso estudo que os editais de recursos financeiros disponibilizados pelo MS, no período de 2012 a 2020, têm sido publicados com regularidade anual e com destinação específica de aplicação. Foram contempladas várias ações: apoio à estruturação e consolidação de Farmácia Viva, APL e AF em PMF, desenvolvimento e registro sanitário de fitoterápicos, aquisição de equipamentos, material de consumo, contratação de serviços, fortalecimento de laboratórios públicos ou parcerias público-privadas, produção e dispensação de plantas medicinais e fitoterápicos e qualificação técnica dos profissionais.

No período observado, 117 municípios (SMS) e 9 estados (SES) foram contemplados com os recursos do MS, por atenderem às exigências, tais como: análise de mérito e análise técnico-econômica do projeto, relevância e capacidade técnica para sua execução, consideração da tradição cultural e popular da comunidade, perfil epidemiológico local, necessidades de saúde da população e promoção do uso racional de medicamentos.

Observamos que os projetos contemplados com os recursos se concentram nas regiões Sudeste, Nordeste e Sul. A população média nessas três regiões decresce nesta mesma ordem. Por outro lado, as regiões Norte e Centro-Oeste apresentam a menor população média e a menor destinação de recursos, sendo que a região Norte arrecadou 5,79\% do montante disponibilizado, com três estados não participando dos editais nesse período. Entretanto, é importante destacar que o Centro-Oeste é a região com maior renda per capita média e participação menos expressiva na captação de recursos do MS e desenvolvimento das Farmácia Viva.

Nesse sentido, constatamos que a realidade sociodemográfica das regiões brasileiras é discrepante e não reflete a busca pela garantia de acesso à saúde, pois a população nas regiões de maior porte e com menor renda média tem menor acesso aos tratamentos de saúde com os medicamentos alopáticos, devido ao seu maior custo e menor disponibilidade de medicamentos fornecidos pelo SUS (Nascimento et al., 2017). Segundo De La Cruz (2005), o acesso a medicamentos é um componente essencial que contribui para a inclusão social e a busca da equidade. Entretanto, apesar de o acesso a medicamentos por meio do SUS ser universal, igualitário e gratuito a todo cidadão, existem desigualdades de acesso a medicamentos entre as regiões brasileiras, com menor acesso nas regiões mais desfavorecidas economicamente, representadas em grande parte por uma população socialmente vulnerável que depende exclusivamente da obtenção de medicamentos por meio do SUS (Oliveira et al., 2019). 
Francisco et al. (2013), ao analisarem desigualdades sociodemográficas em fatores de risco e proteção à saúde, também relatam que algumas doenças resultam da atuação dos determinantes sociais sobre a saúde da população, que, por sua vez, estabelecem posições socioeconômicas, gerando hierarquias de poder e de acesso a recursos básicos, entre eles os relacionados à promoção à saúde e prevenção de agravos. Nesse sentido, para realizar a implementação de ações de promoção à saúde, é preciso conhecer e considerar as realidades locais, detectando a privação de atendimento por que passa a população e considerando dados sociodemográficos da região.

Assim, as estratégias de manutenção e fortalecimento dos programas de fitoterapia no SUS, com a regionalização dos programas por meio de políticas estaduais e da própria articulação e cooperação entre os programas municipais (Ribeiro, 2019), podem fortalecer na assistência farmacêutica o uso da fitoterapia, contribuindo para transformar os contextos de saúde, ambiente e condições de vida nessas regiões. Tal como ocorreu com a publicação da Portaria 1.850/2016, que aprovou o repasse de aproximadamente 1 milhão de reais para desenvolver projetos de AF em PMF exclusivamente da região Norte do Brasil, uma região com maior fragilidade sociodemográfica e econômica.

Apesar de a disponibilidade de recursos ao longo desses nove anos (2012 a 2020) ter contribuído para a expansão do Programa Farmácia Viva no Brasil, vários problemas têm sido relatados. Há dificuldades de execução desses recursos, formalização das parcerias, demora nos trâmites administrativos e jurídicos (Ferreira et al., 2017), dificuldades para a aquisição de insumos vegetais ou medicamentos fitoterápicos acabados através de processos licitatórios (Ribeiro, 2019; Antonio et al., 2014; Ferreira et al., 2017). Além disso, há déficit na qualificação de recursos humanos existentes, descontinuidade do programa em função de mudanças no governo, troca do quadro de funcionários e resistência e/ou ausência de apoio de gestores para investir em infraestrutura e compra de equipamentos (Antonio et al., 2014; Brasil, 2021). A partir dos dados obtidos em nosso trabalho, averiguamos que há captação desigual desses recursos quando consideramos as necessidades regionais, e observamos que a formação dos agentes públicos para a participação nos editais e políticas públicas regionais tornam-se demandas importantes para mudar esse cenário.

Em relação ao progresso global no uso das plantas medicinais e fitoterápicos, nas últimas décadas, a OMS constatou que um maior número de países está reconhecendo o papel dessa terapêutica em seus sistemas de saúde e o número de EstadosMembros com um sistema de registo de medicamentos à base de plantas é maior no Sudeste Asiático (91\%), seguido pela Europa (85\%), Mediterrâneo Oriental (81\%), Américas (54\%), África (49\%) e Pacífico Ocidental (41\%) (WHO, 2019). Entretanto, também encontram dificuldades e sofrem com a falta de apoio financeiro para pesquisas, monitoramento de segurança dos produtos, sistemas de informação, vontade política e integração aos sistemas de saúde. Mas a OMS acredita que é importante atualizar e melhorar a estratégia de medicina tradicional e complementar, a regulamentação, realizar avanços em pesquisa e desenvolvimento, e integrar os sistemas de saúde (WHO, 2019). Nesse sentido, ressalta-se a importância da parceria entre instituições de ensino, pesquisa e tecnologia, indústrias, cooperativas, ONGs e agricultores familiares, juntamente com o poder público, promovendo mudanças em uma sociedade sob evidentes desigualdades sociais (Ferreira et al., 2017; Brasil, 2012).

\section{Conclusões}

As ações e políticas públicas e regulatórias contribuíram tanto para o reconhecimento do uso das plantas medicinais e fitoterápicos, como para o desenvolvimento, institucionalização e regulamentação das Farmácia Viva. Dessa forma, foi possível constatar que houve a expansão dos programas de fitoterapia pelo Brasil e a implementação do Programa Farmácia Viva no âmbito do SUS. Observamos que houve a disponibilização de recursos financeiros com regularidade e destinação específica para estruturação dos serviços de fitoterapia. A participação dos estados na captação desses recursos, porém, foi desigual e sem a consideração das realidades sociodemográficas nas regiões brasileiras. Dessa forma, enfatizamos a necessidade de maior aporte 
financeiro para as regiões de maior fragilidade socioeconômica, a desburocratização na participação dos editais e o fortalecimento das políticas públicas regionais.

\section{Financiamento}

Esta pesquisa foi apoiada pelo Conselho Nacional de Desenvolvimento Científico e Tecnológico (CNPq), Brasil, pela Coordenação de Aperfeiçoamento de Pessoal de Nível Superior - Brasil - (CAPES) - Código Financeiro 001 e Universidade Federal de Mato Grosso do Sul (UFMS).

\section{Referências}

Antonio, G. D., Tesser, C. D., \& Moretti-Pires, R. O. (2014). Phytotherapy in primary health care. Revista de Saúde Pública. https://oi.org/10.1590/S00348910.2014048004985

Balbino, E. E., \& Dias, M. F. (2010). Farmacovigilância: um passo em direção ao uso racional de plantas medicinais e fitoterápicos. Revista Brasileira de Farmacognosia, 20(6): 992-1000. https://doi.org/10.1590/S0102-695X2010005000031.

Bonfim, D. Y. G., Bandeira, M. A. M., Gomes, A. B., Brasil, A. R. L., Magalhães, K. do N., \& Sá, K. M. (2019). Diagnóstico situacional das farmácias vivas existentes no Estado do Ceará. JMPHC | Journal of Management \& Primary Health Care . https://doi.org/10.14295/jmphc.v9i0.543

Brasil. (1994). Ministério da Saúde. Agência Nacional de Vigilância Sanitária (ANVISA). Portaria n. 123 de 19 de outubro de 1994 . Estabelece as normas para o registro de produtos fitoterápicos, de acordo com o regulamento anexo. Diário Oficial da União. 20 out 1994; 132 (200 - seção 1).

Brasil. (1996). Ministério da Saúde. Agência Nacional de Vigilância Sanitária (ANVISA) . Portaria n. 90 de 13 de junho de 1996. Divulga, em anexo, a lista de fármacos, plantas medicinais e adjuvantes de tecnologia farmacêutica, ora em estudo na CPRFB, para compor o fascículo 2 da parte II - monografia da farmacopeia Brasileira IV, de acordo com prioridades solicitadas pela Ceme (Rename), tendo em vista a demandas e necessidade terapêutica. Diário Oficial da União. 14 jun 1996; 134(114 - seção 1): 10481-10482.

Brasil. (2004a). Ministério da Saúde. Agência Nacional de Vigilância Sanitária (ANVISA). Resolução RE n. 90 , de 16 de março de 2004. Guia para a realização de estudos de toxicidade pré-clínica de fitoterápicos. Diário Oficial da União. 18 mar 2004; 141(53 - seção 1): 34-35.

Brasil. (2004b). Conselho Nacional de Saúde. Resolução CNS n. 338, de 06 de maio de 2004. Aprova a Política Nacional de Assistência Farmacêutica. Diário Oficial da União. 20 mai 2004; 141(96 - seção 1): 52-53.

Brasil. (2006a). Secretaria de Atenção à Saúde, Departamento de Atenção Básica. Política Nacional de Práticas Integrativas e Complementares no SUS - PNPICSUS. Ministério da Saúde; 2006 http://bvsms.saude.gov.br/bvs/publicacoes/pnpic.pdf.

Brasil. (2006b). Secretaria de Ciência, Tecnologia e Insumos Estratégicos, Departamento de Assistência Farmacêutica. Política Nacional de Plantas Medicinais e Fitoterápicos. Brasília: Ministério da Saúde; 2006. https://bvsms.saude.gov.br/bvs/publicacoes/politica_nacional fitoterapicos.pdf.

Brasil. (2009). Ministério da Saúde. Relação Nacional de Plantas Medicinais de Interesse ao SUS. Espécies vegetais. DAF/SCTIE/MS - RENISUS. https://portalarquivos2.saude.gov.br/images/pdf/2014/maio/07/renisus.pdf

Brasil. (2010). Gabinete do Ministro. Portaria n. 886, de 20 de abril de 2010. Institui a Farmácia Viva no âmbito do Sistema Único de Saúde (SUS). Diário Oficial da União. 22 abr 2010; 147(75 - seção 1): 75.

Brasil. (2011). Ministério da Saúde. Agência Nacional de Vigilância Sanitária (ANVISA). Formulário de Fitoterápicos da Farmacopeia Brasileira. Brasília: Anvisa; 2011. 126 p.

Brasil. (2012). Secretaria de Atenção à Saúde. Departamento de Atenção Básica. Práticas integrativas e complementares: plantas medicinais e fitoterapia na Atenção Básica $\quad$ [Internet]. $\quad$ Brasília: $\quad$ Ministério $\quad$ da $\quad$ Saúde; $154 \quad 2012 . \quad$ p. https://bvsms.saude.gov.br/bvs/publicacoes/praticas_integrativas_complementares_plantas_medicinais_cab31.pdf.

Brasil. (2013a). Ministério da Saúde. Agência Nacional de Vigilância Sanitária (ANVISA). RDC n. 18 de 03 de abril de 2013 . Dispõe sobre as boas práticas de processamentos e armazenamento de plantas medicinais, preparação e dispensação de produtos magistrais e oficiais de plantas medicinais e fitoterápicos em farmácias vivas no âmbito do Sistema Único de Saúde (SUS). Diário Oficial da União. 5 abr 2013; 150(65 - seção 1): 67-71.

Brasil. (2013b). Ministério da Saúde. Agência Nacional de Vigilância Sanitária (ANVISA). RDC n. 13 de 14 de março de 2013 . Dispõe sobre boas práticas de fabricação de produtos tradicionais fitoterápicos. Diário Oficial da União. 15 mar 2013; 150(51 - seção 1): 50-56.

Brasil. (2013c). Portaria n. 1.555, de 30 de julho de 2013. Dispõe sobre as normas de financiamento e de execução do Componente Básico da Assistência Farmacêutica no âmbito do Sistema Único de Saúde (SUS). Diário Oficial da União. 31 jul 2013; 150(146 - Seção 1): $71-72$.

Brasil. (2014a). Ministério da Saúde. Agência Nacional de Vigilância Sanitária (ANVISA). IN n. 2 de 13 de maio de 2014 . Publica a "Lista de medicamentos fitoterápicos de registro simplificado" e a "Lista de produtos tradicionais fitoterápicos de registro simplificado". Diário Oficial da União. 14 mai 2014 ; $151(90$ seção 1): 58-61. 
Brasil. (2014b). Ministério da Saúde. Agência Nacional de Vigilância Sanitária (ANVISA). RDC n. 26 de 13 de maio de 2014. Dispõe sobre o registro de medicamentos fitoterápicos e o registro e a notificação de produtos tradicionais fitoterápicos. Diário Oficial da União. 14 mai 2014; 151(90 - seção 1): 52-58.

Brasil. (2016). Ministério da Saúde. Agência Nacional de Vigilância Sanitária (ANVISA). RDC n. 84 de 17 de junho de 2016. Aprova o Memento Fitoterápico da Farmacopeia Brasileira e dá outras providências. Diário Oficial da União. 20 jun 2016; 153(116 - seção 1): 70.

Brasil. (2017). Portaria de consolidação n. 5, de 28 de setembro de 2017. Consolidação das normas sobre as ações e os serviços de saúde do Sistema Único de Saúde. Diário Oficial da União. 3 out 2017; 154(190 - Suplemento).

Brasil. (2021). Programa de Fitoterápico e Plantas Medicinais [Internet]. Brasília: Ministério da Saúde; 2021 https://www.gov.br/saude/pt-br/acesso-ainformacao/acoes-e-programas/programa-de-fitoterapico-e-plantas-medicinais.

Carvalho, J. G. (2017). Farmácia viva SUS/Betim - um relato de experiência exitosa na implantação da fitoterapia no SUS. In: Anais do I Congresso Nacional de Práticas Integrativas e Complementares em Saúde (CONGREPICS) [Internet]; Natal: UFRN; https://www.editorarealize.com.br/artigo/visualizar/31837.

Council of Europe. (2019). European pharmacopoeia. 10th. ed. Strasbourg: Council of Europe; 4370 p.

De La Cruz, M. G. (2005). O acesso aos fitoterápicos e plantas medicinais e a inclusão social - diagnóstico situacional da cadeia produtiva farmacêutica no estado de Mato Grosso [Internet]. Cuiabá: Secretaria de Estado de Saúde. 91 p. https://www.ppmac.org/sites/default/files/diagnostico_situacional.pdf

European Medicines Agency (EMA), (2021). Medicines. [Internet]. Amsterdam: European Medicines Agency. https://www.ema.europa.eu/en/medicines/field_ema_web_categories\%253Aname_field/Herbal?search_api_views_fulltext=medicinal\%20plants\%20normative.

Ferreira, L. L. C., Mattos, J. L. C., Oliveira, \& D. R., Behrens, M. D. (2017). Incentivo governamental para Arranjos Produtivos Locais de Plantas Medicinais e Fitoterápicos no âmbito do SUS. Revista Fitos. 11(1): 54-61. https://doi.org/10.5935/2446-4775.20170015.

Figueredo, C. A., Gurgel, I. G. D., \& Gurgel Junior, G. D. (2014). A Política Nacional de Plantas Medicinais e Fitoterápicos: construção, perspectivas e desafios. Physis. 24(2): 381-400. https://doi.org/10.1590/S0103-73312014000200004.

Francisco, P. M. S. B., Barros, M. B. A., Segri, N. J., Alves, M. C. G. P., César, C. L. G., Carandina, L, et al. (2013). Comparação das estimativas de prevalência de indicadores de saúde no Município de Campinas, São Paulo, Brasil, nos anos de 2001/2002 (ISA-SP) e 2008/2009 (ISA-Camp). Cadernos de Saúde Pública; 29(6): 1149-1160. https://doi.org/10.1590/S0102-311X2013000600012.

Ichim, M. C., Häser, A., \& Nick, P. (2020). Microscopic Authentication of Commercial Herbal Products in the Globalized Market: Potential and Limitations. Frontiers in Pharmacology, 11: 876. https://doi.org/10.3389/fphar.2020.00876.

Magalhães, F. (2019). Acesso às Práticas Integrativas e Complementares em Saúde no SUS: uma análise sob a ótica dos usuários [dissertação de mestrado]. Vitória: Universidade Federal do Espírito Santo. 134 p.

Nascimento, R. F., Nunes, V. B., Dias, F. S., Marques, J. M., \& Machado, T. B. (2017). Plantas medicinais e a extensão universitária como estratégia de fortalecimento de uma cooperativa de agricultores no leste fluminense. $E L O ; 6(2): 36-45$. https://doi.org/10.21284/elo.v6i2.232.

Oliveira, L. C. F., Nascimento, M. A. A., \&, Lima, I. M. S. O. (2019). O acesso a medicamentos em sistemas universais de saúde - perspectivas e desafios. Saúde em Debate; 43(spe5): 286-298. https://doi.org/10.1590/0103-11042019S523.

Pereira, N. V., David, M., \& Pasa, M. C. (2017). Farmácia viva: cultivo e manejo de plantas medicinais no horto florestal, Cuiabá-MT, Brasil. In: Pasa, M. C., \& David, M., coordenadores. Múltiplos Olhares sobre a Biodiversidade. Cuiabá: EdUFMT; Carlini \& Caniato Editorial; 5, 491-513. https://doi.org/10.29142/mosb5-28.

Pereira, J. B. A., Rodrigues, M. M., Morais, I. R., Vieira, C. R. S., Sampaio, J. P. M., Moura, M. G., Damasceno, M. F. M., Silva, J. N., Calou, I. B. F., Deus, F. A., Peron, A. P., Abreu, M. C., Militão, G. C. G. \& Ferreira, P. M. P (2015). O papel terapêutico do Programa Farmácia Viva e das plantas medicinais no centrosul piauiense. Revista Brasileira de Plantas Medicinais; 17(4): 550-561. https://doi.org/10.1590/1983-084X/14_008.

Randal, V. B., Behrens, M. D. D., Pereira, A. M. S. (2016). Farmácia da natureza: um modelo eficiente de farmácia viva. Revista Fitos; 10(1): 73-76. https://doi.org/10.5935/2446-4775.20160007

Reports, G. M. ([s.d.]). Herbal Supplements Market-Global Industry Analysis, Growth, Share, Size, Trends, and Forecast | Growth Market Reports. https://growthmarketreports.com/report/herbal-supplements-market-global-industry-analysis

Ribeiro, L. H. L. (2019). Análise dos programas de plantas medicinais e fitoterápicos no Sistema Único de Saúde (SUS) sob a perspectiva territorial. Ciência \& Saúde Coletiva; 24(5): 1733-1742. https://doi.org/10.1590/1413-81232018245.15842017.

Robinson, M. M., \& Zhang, X. (2011) The World Medicines Situation 2011 - Traditional Medicines: Global Situation, Issues and Challenges. Geneva: World Health Organization. $14 \mathrm{p}$.

Rufino, L. L., Gamarra-Rojas, G, Bandeira, M. A. M., Souza, J. R. F., \& Reis, J. N. P. (2018). Prática das farmácias vivas do município de Fortaleza, Ceará, e a necessidade de uma ação de extensão sistêmica. Extensão Rural; 25(4): 40-56. https://doi.org/10.5902/2318179625598.

Sá, K. M. (2016). A repercussão da política nacional de plantas medicinais e fitoterápicos na formação superior em saúde no estado do Ceará entre 2006 e 2016 [dissertação de mestrado]. Fortaleza: Universidade Federal do Ceará. 215 p.

Secretaria de Saúde do Distrito Federal. (2021). Fitoterápicos da Farmácia Viva são distribuídos em 22 unidades básicas de saúde [Internet]. Brasília: Secretaria de Estado em Saúde. https://www.saude.df.gov.br/fitoterapicos-da-farmacia-viva-sao-distribuidos-em-22-unidades-basicas-de-saude/.

U.S. Food and Drug Administration. (FDA). (2021). Official website. [Internet]. Washington, D.C.: U.S. Food and Drug Administration. https://www.fda.gov/. 
Research, Society and Development, v. 11, n. 2, e22211225524, 2022

(CC BY 4.0) | ISSN 2525-3409 | DOI: http://dx.doi.org/10.33448/rsd-v11i2.25524

U.S. Pharmacopeia (USP). (2021). Official website. North Betesda (MD): United States Pharmacopoeial Convention. https://www.usp.org/.

World Health Organization (WHO). (2013). WHO Traditional Medicine Strategy. 2014-2023. Geneva: World Health Organization. 78 p.

World Health Organization (WHO). (2019). WHO Global Report on Traditional and Complementary Medicine 2019 World Health Organization. https://www.who.int/traditional-complementary-integrative-medicine/WhoGlobalReportOnTraditionalAndComplementaryMedicine2019.pdf. 